\title{
ESTUDO FLORÍSTICO E FITOSSOCIOLÓGICO DE UM TRECHO DE MATA CILIAR DO RIO JACUIIPE EM FEIRA DE SANTANA, BAHIA, BRASIL.
}

\author{
Marise Carvalho ${ }^{1}$; Flavio França ${ }^{2}$; Efigênia de Melo $^{3}$ e Robson de Jesus Santos ${ }^{4}$ \\ 1. Bolsista PROBIC/UEFS, Graduanda em Ciências Biológicas, Universidade Estadual de Feira de Santana email: \\ marisecarvalho.tec@gmail.com \\ 2. Orientador, Departamento de Ciências Biológicas, Universidade Estadual de Feira de Santana, e-mail: \\ franca.flavio@gmail.com \\ 3. Participante do projeto Departamento de Ciências Biológicas, Universidade Estadual de Feira de Santana, e-mail: \\ efidemelo@hotmail.com \\ 4. Participante do projeto, Departamento de Ciências Biológicas, Universidade Estadual de Feira de Santana, e-mail: \\ robssantos17@hotmail.com
}

PALAVRAS-CHAVE: Domínio Caatinga, Semiárido, Bacia do Rio Paraguaçu

\section{INTRODUÇÃO}

A mata ciliar é uma vegetação essencial ao equilíbrio ambiental essas formações vegetativas margeiam as nascentes e os cursos d'água, e são também conhecidas como matas de galeria, floresta ripária e matas de ribeirinha. Estas formações são extremamente importantes frente aos benefícios que apresentam, controlando a erosão das margens dos rios, reduzindo os efeitos de enchentes, mantendo a qualidade e a quantidade da água, realizando a filtragem de resíduos químicos, e contribuindo para a manutenção da biodiversidade local (Chaves, 2009).

Segundo Venancio (2007), atualmente o termo mata ciliar e qual sua importância na incorporação dos recursos hídricos está sendo de grande preocupação na sociedade, pois se tratam de uma proteção às laterais dos rios, córregos, reservatórios e lagos urbano, sendo assim uma Área de Preservação Permanente (APP), que conforme a Resolução do CONAMA no 302 , Art. $2^{\circ}$, II, tem função ambiental de preservar os recursos hídricos, a paisagem, a estabilidade geológica, a biodiversidade o fluxo gênico de fauna e flora, proteger o solo e assegurar o bem estar das populações humanas

Mesmo apresentando tais benefícios, é perceptível o alto índice de devastação destas matas, seja para expansão de áreas agrícolas por apresentar um solo relativamente fértil e proximidade dos corpos d'água, o que facilita as instalações de sistemas irrigáveis, ou pela expansão urbana num crescimento desordenado das cidades (Castro et al., 2012). Este cenário revela a necessidade de recuperação destas formações, para que ocorra a diminuição dos diversos problemas que se desencadeiam e para que se possa atender à legislação que considera estes espaços como Áreas de Preservação Permanente.

Para que ocorra a recuperação destas formações vegetativas se faz necessário o conhecimento das espécies que compõem estes espaços e das suas exigências, para que partindo destas informações, planos eficientes sejam desenvolvidos e ocorra uma recuperação efetiva o mais próximo possível de um ambiente natural. Nesta intensão o presente trabalho buscou realizar estudos florísticos e fitossociológicos numa área de mata ciliar do Rio Jacuípe, um rio perene que tem sua nascente na cidade de Morro do Chapéu e passa por diversos municípios dentre eles Feira de Santana onde se concentrou os estudos, e segue seu curso até desaguar no Rio Paraguaçu, com o objetivo de caracterizar a vegetação da mata ciliar encontrada às margens deste rio.

\section{METODOLOGIA}

A pesquisa foi realizada numa fração do Rio Jacuípe o qual é um rio perene, genuinamente baiano, com nascente na Chapada Diamantina, mais especificamente no município de Morro do Chapéu, no estado da Bahia, em seu percurso perpassa municípios como Anguera, 
Conceição do Coité, Feira de Santana, Morro do Chapéu, Santa Bárbara, dentre outros, até atingir o rio Paraguaçú, do qual é tributário de margem esquerda (Gomes e Lobão, 2009). A fração de mata ciliar estudada situa-se às margens do Rio que perpassa o município de Feira de Santana, e que possui domínio morfoclimático da Caatinga, e grande parte desta área se encontra já degradada por ação antrópica. (Gomes e Lobão, 2009).

Foram realizados levantamentos florísticos para o conhecimento da biodiversidade, e estudos fitossociológico para ajudar a compreender os agrupamentos de plantas, sua interdependência e relação com fatores bióticos e abióticos. Para o levantamento destes dados foi utilizado o método do ponto quadrante descrito por Mueller-Dombois \& Ellenberg (1974). Foram feitos transectos perpendiculares à margem do rio de $50 \mathrm{~m}$ de extensão, com pontos de levantamentos avaliados de 10 em 10 metros, a partir do ponto zero. Foram feitos 17 transectos distanciados por metros seguindo a margem do rio.

Os dados encontrados foram registrados em uma ficha de campo e trabalhados no programa FITOPAC 2.0 (Shepherd, 2011), produzindo uma tabela de IVI (índice valor de importância) (Rodal, 1992). A identificação taxonômica de cada material coletado será realizada utilizando a classificação APG III (Angiosperm Phylogeny Group III, 2009) e com o auxílio de bibliografias especializadas.

\section{RESULTADOS E DISCUSSÃO}

A área de mata amostrada neste trabalho de aproximadamente $800 \mathrm{~m}$ seguindo a margem do rio, por $50 \mathrm{~m}$ metros de largura adentrando a mata, totalizando $40.000 \mathrm{~m}^{2}$, onde foram 17 transectos com 102 pontos no total. Observamos que esta mata ciliar encontrasse bastante desmatada, com árvores que apresentam distâncias entre si superiores a quarenta metros, deixando assim uma grande área de solo descoberta, o que favorece a ocorrência de processos erosivos, assoreamento do rio e contribui para uma série de problemas, o que está de acordo com Mocellin (2004) que afirma que a ausência da cobertura vegetal da mata ciliar altera as condições locais gerando desequilíbrio ecológico de grandes dimensões.

No levantamento florístico foram registradas 408 indivíduos distribuídos em 65 espécies, 56 gêneros e 25 famílias, sendo a família Leguminosae (Fabaceae) a mais representativa com 142 $(34,8 \%)$ indivíduos, seguida de Rhammaceae com 42 (10,3\%), Anacardiaceae com 28 (6,9\%), Rutaceae e Euphorbiaceae com 27 (6,6\%) ambas, Meliaceae e Rubiaceae com 17 (4,1\%). Essa representatividade de Leguminosae concorda com estudos de Santos (2012), e corrobora estudos de Queiroz (2009).

Em relação aos parâmetros fitossociológicos foram avaliados os valores relativos da frequência, dominância e densidade, além do Índice Valor de Importância (IVI) e de cobertura (IVC) (Tabela1) para os indivíduos.

Tabela 1: Principais valores dos parâmetros avaliados para as espécies mais importantes da mata avaliada.

\begin{tabular}{llccccc}
\hline Espécie & $\begin{array}{c}\text { NInd } \\
(\boldsymbol{\%})\end{array}$ & $\begin{array}{c}\text { RelFr } \\
(\boldsymbol{\%})\end{array}$ & $\begin{array}{c}\text { RelDo } \\
(\boldsymbol{\%})\end{array}$ & $\begin{array}{c}\text { RelDe } \\
(\boldsymbol{\%})\end{array}$ & IVI & IVC \\
\hline Mimosa Tenuiflora (Willd.) Poir. & 52 & $\mathbf{1 2 , 7 5}$ & 22,48 & 12,75 & 47,97 & 35,22 \\
\hline Ziziphus joazeiro Mart. & 42 & 10,29 & 17,60 & 10,29 & 38,19 & 27,89 \\
\hline Caesalpinia piramidales Tul. & 30 & 7,35 & 9,56 & 7,35 & 24,27 & 16,91 \\
\hline Cereus jamacaru DC. & 24 & 5,88 & 4,77 & 5,88 & 16,54 & 10,65 \\
\hline Zanthoxylum petiolare A. St.-Hil. \& Tul. & 27 & 6,62 & 1,65 & 6,62 & 14,88 & 8,26 \\
\hline Senegalia bahiensis (Benth.) Seigler \& Ebinger & 27 & 6,62 & 1,17 & 6,62 & 14,41 & 7,79 \\
\hline Trichilia hirta L. & 17 & 4,17 & 2,52 & 4,17 & 10,85 & 6,68 \\
\hline Ruprechtia laxiflora Meisn. & 6 & 1,47 & 7,62 & 1,47 & 10,56 & 9,09 \\
\hline Commiphora leptophloeos (Mart.) J.B. Gillett & 7 & 1,72 & 5,74 & 1,72 & 9,17 & 7,46 \\
\hline Randia armata (Sw.) DC. & 16 & 3,92 & 0,48 & 3,92 & 8,33 & 4,41 \\
\hline Crateva tapia L. & 8 & 1,96 & 3,44 & 1,96 & 7,36 & 5,40 \\
\hline Celtis iguanaea (Jacq.) Sarg. & 12 & 2,94 & 0,65 & 2,94 & 6,54 & 3,59 \\
\hline Mangifera indica L. & 3 & 0,74 & 5,01 & 0,74 & 6,48 & 5,75 \\
\hline
\end{tabular}




\begin{tabular}{|c|c|c|c|c|c|c|}
\hline Cnidoscolus urens (L.) Arthur & 12 & 2,94 & 0,21 & 2,94 & 6,09 & 3,15 \\
\hline Albizia inundata (Mart.) Barneby \& J.W. Grimes & 7 & 1,72 & 2,28 & 1,72 & 5,71 & 4,00 \\
\hline Schinopsis brasiliensis Engl. & 5 & 1,23 & 2,06 & 1,23 & 4,51 & 3,29 \\
\hline Spondias sp. & 8 & 1,96 & 0,17 & 1,96 & 4,10 & 2,13 \\
\hline Spondias mombin L. & 4 & 0,98 & 1,77 & 0,98 & 3,73 & 2,75 \\
\hline Anona squamosa L. & 5 & 1,23 & 1,12 & 1,23 & 3,57 & 2,35 \\
\hline Maytenus acanthophylla Reissek. & 6 & 1,47 & 0,23 & 1,47 & 3,17 & 1,70 \\
\hline Senegalia langsdorffii (Benth.) Seigler \& Ebinger & 6 & 1,47 & 0,21 & 1,47 & 3,15 & 1,68 \\
\hline Solanum paniculatum L. & 6 & 1,47 & 0,04 & 1,47 & 2,99 & 1,51 \\
\hline Cordia globosa (Jacq.) Kunth & 3 & 0,74 & 1,33 & 0,74 & 2,81 & 2,07 \\
\hline Sebastiania brasiliensis Spreng. & 5 & 1,23 & 0,26 & 1,23 & 2,71 & 1,48 \\
\hline Byttneria filipes Mart. Ex K. Schum. & 5 & 1,23 & 0,07 & 1,23 & 2,52 & 1,30 \\
\hline
\end{tabular}

Legenda: NInd - Numero de indivíduos; RelFr - Frequência Relativa; RelDo - Dominência Relativa; RelDe - Densidade Relativa; IVI - Índice Valor de Importância e IVC - Índice Valor de Cobertura

Em relação à Frequencia relativa e a densidade relativa e dominância relativa observamos que os indivíduos de maior importância foram Mimosa tenuiflora (Willd.) Poir. (Leguminosae (Fabaceae)), Ziziphus joazeiro Mart.(Rhammaceae) e Cenostigma pyramidale (Tul.) Gagnon \& G.P. Lewis (Leguminosae (Fabaceae)), pois apresentam os valores mais altos, e como os valores de IVI é resultado da soma destes outros a ordem de importância foi mantida, tendo estas três espécies como as mais representativas da mata. Apesar de Cereus jamacaru DC. (Cactáceae) Zanthoxylum petiolare A. St.-Hil. \& Tul. (Rutaceae), Senegalia bahiensis (Benth.) Seigler \& Ebinger (Leguminosae (Fabaceae)), Trichilia hirta L. (Meliaceae) e Randia armata (Sw.) DC., apresentarem números de indivíduos também significativos, os valores que apresentaram para os parâmetros avaliados faram baixos. Algo que cabe destaque são os valores apresentados para a Dominância Relativa das espécies Ruprechtia laxiflora Meisn. (Polygonaceae) (7,62 \%) e Senegalia bahiensis (Benth.) Seigler \& Ebinger, $(1,17 \%)$ pois ambas apareceram numa frequência bastante distinta se observamos a quantidade de indivíduo relativa a cada uma, 6 e 27 respectivamente. Isto se explica pelo fato que embora a espécie tenha sido representada por apenas 6 indivíduos os seus troncos apresentavam diâmetro em média em relação aos 27 representantes da Senegalia bahiensis (Benth.) Seigler \& Ebinger,. Esta diferença nos valores refletiu também nos valores do IVC, por ter influência direta na cobertura da área os diâmetros que cada árvores apresenta. Porém em relação ao IVI, Cereus jamacaru DC., aparece com 16,54, Zanthoxylum petiolare A. St.-Hil. \& Tul., com 16,54 e Senegalia bahiensis (Benth.) Seigler \& Ebinger, que apresenta 14,41. Tanto o Zanthoxylum petiolare A. St.-Hil. \& Tul., quanto a Senegalia bahiensis (Benth.) Seigler \& Ebinger se apresentaram com a mesma quantidade de indivíduos, e valores de IVI bastante diferentes, o que pode ser explicado pelo fato deste índice ter influencia dos valores da dominância relativa e o Zanthoxylum petiolare A. St.-Hil. \& Tul. apresentar valor maior, assim como o Cereus jamacaru DC. em relação à Senegalia bahiensis (Benth.) Seigler \& Ebinger.

\section{CONSIDERAÇÕES FINAIS}

A composição florística da área estudada revelou uma predominância da família Leguminosae com a maior quantidade de indivíduos amostrados, e a espécie Mimosa tenuiflora (Willd.) Poir. como a espécie mais significativa. As avaliações dos parâmetros fitossociológicos permitiram conhecer as espécies mais importantes, bem como a influência que as medidas dos diâmetros que apresentam pode gerar as questões de cobertura e de importância de tal espécie. A mata encontra-se bastante alterara por ações antrópicas e o agravamento destas modificações poderá em algum momento trazer ainda mais problemas relacionados a um desequilíbrio ecológico.

\section{REFERENCIAS}


CASTRO, D.; MELLO, R. S. P.; POESTER, G.C.; Práticas para restauração da Mata ciliar. Porto Alegre: Catarse - Coletivo de Comunicação, 2012.

CHAVES, ADILAR. Importância da mata ciliar (legislação) na proteção dos cursos hídricos, alternativas para sua viabilização em pequenas propriedades rurais. Universidade de Passo Fundo, 19 p. 2009.

GOMES, S. T.; LOBÃO, J. S. Delimitação de sub-bacias a partir do uso de imagem SRTM/NASA: um estudo da Bacia do Rio Jacuípe-BA. Anais XIV Simpósio Brasileiro de Sensoriamento remoto, Natal, Brasil, 25-30 abril 2009, INPE, p. 3841 - 3848.

Licenciamento Ambiental. A importância da mata ciliar. Disponível em: www.licenciamentoambiental.eng.br/a-importancia-da-mata-ciliar/. Acesso em 04 de agosto de 2017.

MOCELLIN, G. Conscientização da Importância da Mata Ciliar no Ensino Fundamental na Região Rural do Município de Colombo-PR. Monografia Especialização. Medianeira: Universidade Tecnológica Federal do Paraná, 2014.

MUELLER, DOMBOIS, D., ELLEMBBERG, H. Aims and methods of vegetation ecology. New York: Wiley and Sons, 1974, 574p.

QUEIROZ, C. Caracterização da vegetação ciliar em rios temporários em uma região do semiárido da Bahia, Brasil. Dissertação. Feira de Santana: Universidade Estadual de Feira de Santana, 2014.

QUEIROZ, L. Leguminosas da caatinga. Recife/Feira de Santana: Universidade Estadual de Feira de Santana/Royal Botanic Gardens, Kew. APNE, ano? 443p.

RODAL, M. J. N. et al. Fitossociologia da vegetação arbustivo-arbóreo em quatro áreas de Caatinga em Pernambuco. 1992. 241f. Tese (Doutorado em Ciências) - Universidade Estadual de Campinas, Campinas, São Paulo. 